\title{
Hava Soğutmalı Bir Benzin Motorunda LPG Uygulamasının Motor Performans ve Egzoz Emisyonlarına Etkisi
}

\author{
Mehmet KUNT ${ }^{1}$, İbrahim MUTLU ${ }^{1}$, Yaşar Önder ÖZGÖREN ${ }^{1}$, Şükrü Ayhan BAYDIR ${ }^{1}$, Muhammed \\ ARSLAN $^{2 *}$ \\ ${ }^{1}$ Afyon Kocatepe Üniversitesi, Teknoloji Fakültesi, Otomotiv Mühendisliği Bölümü, Afyonkarahisar. \\ ${ }^{2}$ Afyon Kocatepe Üniversitesi, Çay Meslek Yüksekokulu, Otomotiv Teknolojisi Bölümü, Afyonkarahisar.
}

e-posta: mehmet5164@hotmail.com

e-posta: ibrahimmutlu@aku.edu.tr

e-posta: yasarozgoren@aku.edu.tr

e-posta: abaydir@aku.edu.tr
ORCID ID: http://orcid.org/0000-0002-2033-6703

ORCID ID: http://orcid.org/0000-0001-5563-1000

ORCID ID: http://orcid.org/0000-0002-0856-0833

ORCID ID: http://orcid.org/0000-0001-7136-7860

*Sorumlu yazar e-posta: arslanmuhammed10@gmail.com ORCiD ID: http://orcid.org/0000-0001-8387-7008

Geliş Tarihi: 23.09.2019; Kabul Tarihi: 23.10.2019

Öz

Bu çalışmada, hava ile soğutmalı ve tek silindirli bir benzin motorunda benzin ve sıvılaştırılmış petrol Anahtar kelimeler LPG; Egzoz emisyonları; Motor performansı; Benzin motoru gazı (LPG) yakıtı ile egzoz emisyon ve motor performans analizi gerçekleştirilmiştir. Deneyler, en yüksek motor torkunun elde edildiği 2600 dev/dk motor devrinde \%20-\%100 gaz kelebeği açıklığında \%20 gaz kelebeği açıklı̆̆ aralıklarla gerçekleştirilmiştir. Sonuçlar LPG yakıtından elde edilen değerler benzine oranla ortalama motor torku ve gücünün $\% 4,15$, ortalama yakıt tüketimi ve özgül yakıt tüketiminin ise sırasıyla \%16,77 ve \%16,45 düştüğünü göstermiştir. Buna ek olarak, LPG yakıtı ile benzine oranla ortalama $\mathrm{CO}, \mathrm{HC}$ ve $\mathrm{CO}_{2}$ emisyonları sırasıyla \%35, \%35,36 ve \%2,5 düşmüş; ortalama $\mathrm{NO}_{\mathrm{x}}$ emisyonu $\% 88$ yükselmiştir.

\section{The Effect Of Lpg Application On Engine Performance And Exhaust Emissions In An Air Cooled Gasoline Engine}

\begin{abstract}
Keywords

LPG; Exhaust

Emissions; Engine

Performance;Spark

Ignition Engine

The exhaust emission and engine performance analysis of LPG and gasoline fuel and engine in single cylinder gasoline engine with air cooling were performed in this paper. The experiments were carried out for throttle openings of $20 \%-100 \%$ with $\% 20$ intervals at $2600 \mathrm{rpm}$, where the engine was most stable. The results showed that the mean engine torque and power decreased $4.15 \%$, average fuel consumption and specific fuel consumption decreased $16.77 \%$ and $16.45 \%$, respectively, comparing to gasoline and LPG. In addition, average $\mathrm{CO}, \mathrm{HC}$ and $\mathrm{CO}_{2}$ emissions of LPG fuel and gasoline decreased by $35 \%, 35.36 \%$ and $2.5 \%$, respectively; average $\mathrm{NO}_{x}$ emission increased by $88 \%$.
\end{abstract}

(c) Afyon Kocatepe Üniversitesi

\section{Giriş}

Gün geçtikçe artan dünya nüfusu, enerji talebini artırmakta ve devletler enerji talebini karşılamak amacıyla öncelikle dünyadaki enerji kaynaklarının çoğunluğunu oluşturan fosil yakıtlara yönelmektedir (Çeçen 2018, Koca 2013). Bu durum yıllar geçtikçe fosil yakıtların artan kullanımı ve rezervlerin hızla azalışı ile sonuçlanmıştır. Dolayısıyla azot oksit
(NOx), karbon monoksit (CO), hidrokarbon (HC) vb. çevre için zararlı olan gazların salınımı günden güne artmış ve yeryüzünün sıcaklığını arttırmıştır. Küresel iklim değişiklikleri pek çok hastalığa sebep olurken su, toprak ve hava gibi önemli yaşam alanları kirlenmiştir (Çelik 2018, Engin 2018, Aravind et al. 2015, Özgören vd. 2013, Balki 2005, Altun 2009, Kim et al. 2016). Mevcut durum bilim dünyasını geleneksel fosil bazlı yakıtların egzoz emisyonlarını 
azaltarak çevreye olan olumsuz etkilerinin minimize edilmesine yöneltmiştir. Dolayısıyla bilim adamları bu konuda araştırmalar yapmaktadır (Keçebaş vd. 2010, Çiçek 2018, Keskin and Çetinkaya 2001).

İçten yanmalı motorlardan beklenilen düşük yakıt tüketimi ile hem düşük egzoz emisyon seviyelerine ulaşmak hem de en yüksek motor performansını elde etmektir. Bu noktada gaz yakıtlar diğer petrol yakıtlarına göre egzoz emisyonlarının düşük olması, homojen bir karışım oluşturulması ve yüksek oktan sayısı gibi avantajlarıyla dikkat çekmektedir. Temel olarak bütan $\left(\mathrm{C}_{4} \mathrm{H}_{10}\right)$ ve propan $\left(\mathrm{C}_{3} \mathrm{H}_{8}\right)$ bileşenlerinden oluşan LPG (Sıvılaştırılmış Petrol Gazı), bu yakıtlardan birisidir. Kimyasal yapısı açısından olefin ve parafin grubunda yer alırlar. Çoğunluğu doğal gazdan ve ham petrolün distile edilmesiyle elde edilir. LPG bileşenlerinin hacmi, yüksek basınçta tutularak azaltılmaktadır (Bilgin 2018, Kocagöz 2009, Aravind et al. 2015, Çınar vd. 2001, Morganti et al. 2013, Mitukiewicz et al. 2015, Sulaiman et al. 2013, Elnajjar et al. 2013, Szpica 2018).

LPG'nin \%61'i doğal gaz üretiminden; \%39'u rafineri üretiminden gelmektedir (Sayın vd. 2005). Önceleri sabit tesis motorlarında kullanılan LPG, günümüzde motorlu araçlarda da kullanılmaya başlanmıştır (Koca 2013). Birçok ülkede olduğu gibi Türkiye'de de LPG'nin yapısındaki bütan ve propan oranları mevsimsel olarak değişmektedir. Genellikle bütan miktarı \%70; propan miktarı \%30 civarındadır (Çiçek 2018).

LPG'nin içeriğindeki ana bileşenler olan propan ve bütanın oktan sayılarının benzinin oktan sayısından yüksek olması LPG'nin de oktan sayısını benzinin oktan sayısından yüksek hale getirmektedir. Bu yüzden LPG benzin motorunda vuruntu oluşturmadan kullanılabilecek alternatif bir yakıt haline gelmiştir (Kart 2009).

Bu çalışmada, hava ile soğutulan bir benzin motoru sırasıyla LPG ve benzinle çalıştırılarak motor performansı ve egzoz emisyon analizi gerçekleştirilmiştir.

\section{Materyal ve Metot}

Deneylerin gerçekleştirilmesi için hava soğutmalı benzin motoruna LPG uygulaması yapılmıştır. Gerekli uyarlamalar tamamlandıktan sonra deneyler gerçekleştirilmiş ve LPG'nin ve benzinin motor performansı ve egzoz emisyonlarına etkisi araştırılmıştır. Benzin motoruna uygulanan LPG sistemi 1. nesil Atiker marka LPG dönüşüm sistemi olup LPG, emme manifoldu üzerinde bulunan karbüratör yoluyla motora gönderilmiştir. Test ortamı, Lombardini marka motor, KEMSAN marka elektrikli dinamometre, BíLSA marka emisyon ölçüm cihazı, ESIT marka yük hücresi ve Densi marka hassas teraziden oluşmaktadır. Deneyler, benzin ve LPG ile motorun maksimum tork devri olan $2600 \mathrm{dev} / \mathrm{dk}$ motor devrinde \%20-\%100 gaz kelebeği açıklığında (GKA) \%20 aralıklarla gerçekleştirilmiştir. Motor yağı sıcaklığı $90^{\circ} \mathrm{C}$ civarında sabit tutulmuştur. Deney ortamı Şekil 1'de, şeması ise Şekil 2'de verilmiştir.

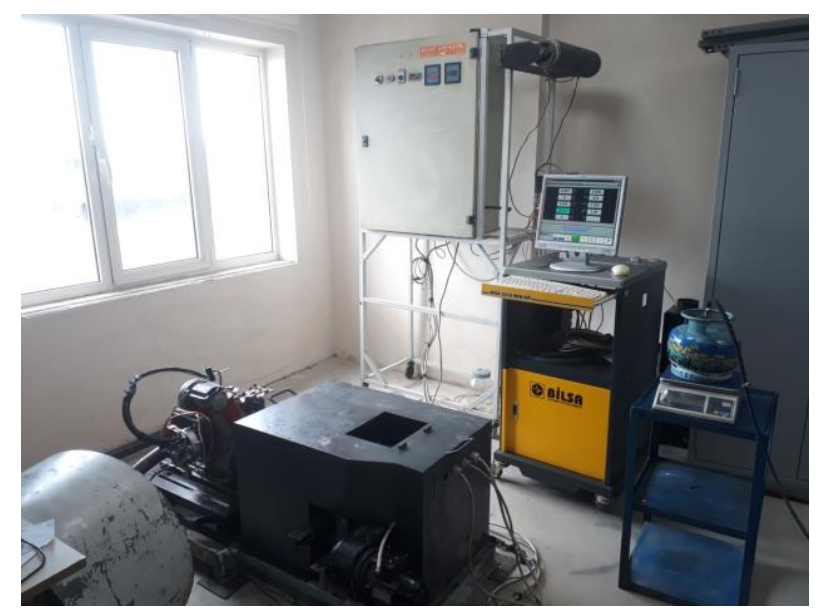

Şekil 1. Deney ortamı. 


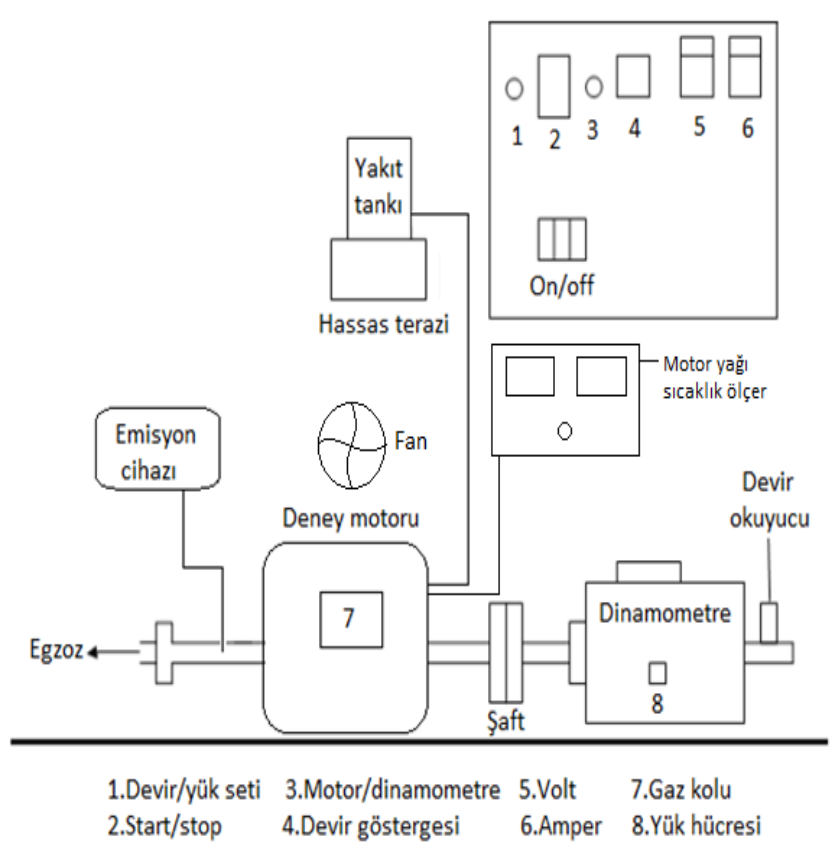

Şekil 2. Deney ortamına ait şematik görünüm.

\subsection{Deney motoru}

Deney motoru tek silindirli ve hava ile soğutulan Lombardini marka LGA $340 \mathrm{OHC}$ model motordur. Motora ait teknik özellikler Çizelge 1'de, motora LPG uygulaması ise Şekil 3'de verilmiştir.

Çizelge 1. Motora ait teknik özellikler.

\begin{tabular}{cc}
\hline Soğutma Sistemi & Hava \\
\hline Motor Tipi & 4 zamanlı \\
\hline Supap Mekanizması & Üstten Tek Egzantrik \\
\hline Silindir sayısı & 1 \\
\hline Silindir çapı (mm) & 82 \\
\hline Strok (mm) & 64 \\
\hline Motor hacmi (cm $\left.{ }^{3}\right)$ & 338 \\
\hline Sıkıștırma oranı & $8,5 / 1$ \\
\hline Max. Güç (kW/HP) (DIN & $7,4 / 10-8,1 / 11$ \\
70020) & $23,7 / 2,4$ \\
\hline Max. tork (Nm/Kgm) & 1,2 \\
\hline Yağ kapasitesi (I) & $342-251$ \\
\hline Yağ tüketimi (g/kWh-g/HPh) & 30 \\
\hline Motorun boş ağırı̆ı̆ı (Kg) & Champion RC12YC \\
\hline Buji & Elektronik \\
\hline Ateşleme sistemi
\end{tabular}

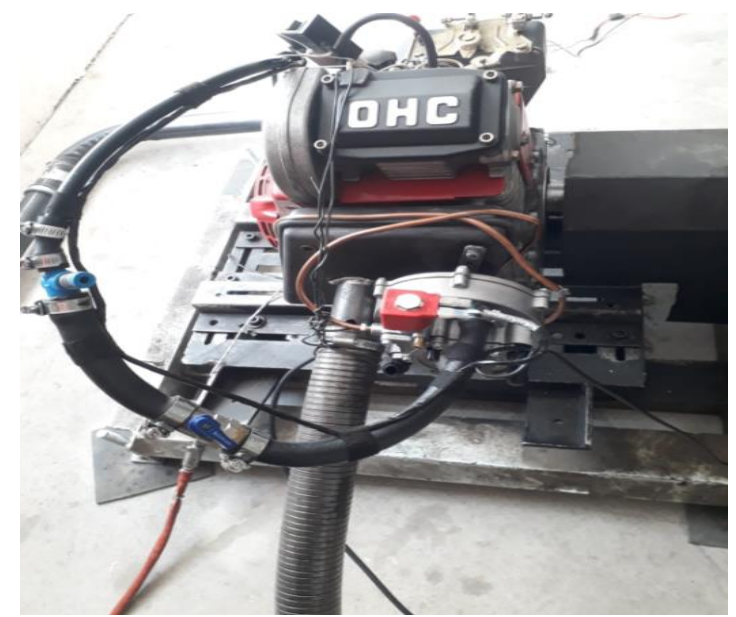

Şekil 3. Motora LPG uygulaması.

\subsection{Emisyon cihazı}

Bilsa MOD 2210 WIN-XP marka emisyon cihazı emisyon ölçümü için kullanılmıştır. Cihaza ait teknik özellikler Çizelge 2'de verilmiştir.

Çizelge 2. Emisyon cihazına ait teknik özellikler.

\begin{tabular}{|c|c|c|}
\hline Parametreler & Ölçme Sınırı & Hassasiyet \\
\hline $\mathrm{CO}$ & $0-\% 10$ & $\% 0,001$ \\
\hline $\mathrm{CO}_{2}$ & $0-\% 20$ & $\% 0,001$ \\
\hline $\mathrm{HC}$ & $0-10000$ & 1 PPM \\
\hline $\mathrm{O}_{2}$ & $0-\% 25$ & $\% 0,01$ \\
\hline CO Corr & $0-\% 10$ & $\% 0,001$ \\
\hline $\mathrm{NO}_{\mathrm{x}}$ & $0-5000$ & 1 PPM \\
\hline Lambda & $0-5,000$ & 0,001 \\
\hline AFR & $0-5,000$ & \\
\hline Motor yağ ısısı & $0-150^{\circ} \mathrm{C}$ & $1{ }^{\circ} \mathrm{C}$ \\
\hline Devir (RPM) & 0-9990 d/dak. & $10 \mathrm{~d} / \mathrm{dak}$. \\
\hline $\begin{array}{c}\text { Opasite (pusluluk } \\
\text { derecesi) }\end{array}$ & $\% 0-100$ & $\% 0,1$ \\
\hline $\begin{array}{c}\text { K (karartma } \\
\text { katsayısı) }\end{array}$ & $0-9,99$ & $0,01 \mathrm{~m}^{-1}$ \\
\hline $\begin{array}{l}\text { Çalışma ortam } \\
\text { sıcaklığı }\end{array}$ & $0{ }^{\circ} \mathrm{C} /+40^{\circ} \mathrm{C}$ & $\% 0,01$ \\
\hline Algılama süresi & $<5 \mathrm{sn}$. & \\
\hline $\begin{array}{l}\text { Ölccüm odası } \\
\text { sıcaklığı }\end{array}$ & $70-100^{\circ} \mathrm{C}$ & \\
\hline Besleme voltajı & $230 \mathrm{VAC}$ & \\
\hline Besleme frekansı & $50 \mathrm{~Hz}$ & \\
\hline Debi & $\begin{array}{l}\text { Min. } 2 \text { It/sn- } \\
\text { Nom. } 4 \text { lt/sn }\end{array}$ & \\
\hline
\end{tabular}

\subsection{Yük hücresi}

ESIT yük hücresi tork ölçümünde kullanılmıştır. Cihaza ait teknik özellikler Çizelge 3 'de gösterilmiştir. 
Çizelge 3. Yük hücresine ait özellikler.

\begin{tabular}{|c|c|}
\hline Loadcell & $8 \operatorname{adet}(350 \mathrm{ohm})$ \\
\hline Giris hassasiyeti & $0.5 \mu \mathrm{V} /$ dijit \\
\hline Hassasiyet & $\% 0.003$ \\
\hline Stabilite & $3.6 \mathrm{ppm} /{ }^{\circ} \mathrm{C}$ \\
\hline A/D dönüștürücü & 24 bit Sigma-Delta \\
\hline Okuma frekansı & $50 \mathrm{~Hz}$ \\
\hline Uyarım voltajı & 10V DC \\
\hline $\begin{array}{c}\text { Çalışma sıcaklı̆̆ aralığı (OIM } \\
\text { onaylı) }\end{array}$ & $-10^{\circ} \mathrm{C} /+40^{\circ} \mathrm{C}$ \\
\hline Depolama sicaklı̆ı aralığı & $-20^{\circ} \mathrm{C} /+70^{\circ} \mathrm{C}$ \\
\hline Çalışma voltajı ve güç & $10-35 \mathrm{~V} \mathrm{DC} / 5 \mathrm{~W}$ \\
\hline Ağırlık & $1 \mathrm{~kg}$ \\
\hline Yük göstergesi & $\begin{array}{c}4.5 \mathrm{~mm}, 40 \text { pixel, } \mathrm{LCD}, 2 \times 16 \\
\text { digit }\end{array}$ \\
\hline
\end{tabular}

\subsection{Hassas terazi}

Yakıt tüketimi ölçümünde, 30 kg'a kadar 1 gram hassasiyetle ölçüm yapabilen Densi PC-100W-30SS marka hassas terazi kullanılmıştır.

\subsection{Kullanılan yakıtların özellikleri}

Deneylerde kullanılan yakıtların özellikleri Çizelge 4'te verilmiştir.

Çizelge 4. Deneylerde kullanılan yakıtların özellikleri.

\begin{tabular}{ccc}
\hline Özellikler & Benzin (95 Oktan) & LPG \\
\hline Stokixometrik Oran & $14,7 / 1$ & $15,6 / 1$ \\
\hline Alt Isıl Değer (MJ/I) & 33,50 & 28,06 \\
\hline Enjeksiyonun Fazı & SIvı & Gaz \\
\hline Alevin Yayılma Hızı & 0,48 & 0,5 \\
(m/s) & & \\
\hline Oktan Sayısı & $80-95$ & $106-111$ \\
\hline Kendi Kendine Tutuşma & $246-280$ & $405-470$ \\
Sıcaklığı ( ${ }^{\circ} \mathrm{C}$ ) & & \\
& & \\
\hline
\end{tabular}

\section{Bulgular}

Deneylerde hava soğutmalı motorda benzin ve LPG'nin motor performansı ve egzoz emisyonlarına etkisi farklı GKA'larda incelenmiştir.

\subsection{Motor performansı}

Deneylerde motor torku, motor gücü, yakıt tüketimi (YT) ve özgül yakıt tüketimi (ÖYT) değerleri GKA'ya bağlı olarak belirlenmiştir. Her iki yakıtla elde edilen veriler karşılaştırımıştır.

Motorun maksimum torku LPG ve benzin için \%100 GKA'da $16,97 \mathrm{Nm}$ ve $17,9 \mathrm{Nm}$ olarak ölçülmüştür. Ortalama motor torku LPG ile benzine oranla $\% 4,15$ azalma göstermiştir. Şekil 4'de artan GKA ile her iki yakıt için silindire daha fazla hava-yakıt karışımı girdiğinden motor torku artış göstermiştir. Buna ilave olarak, LPG yakıtı gaz fazında olduğundan motora giren hava kütlesini azaltmakta ve volümetrik verim düşmektedir. Dolayısıyla motor torkunda LPG kullanımı ile benzine oranla düşüş yaşanmıştır (Duc and Duy 2018).

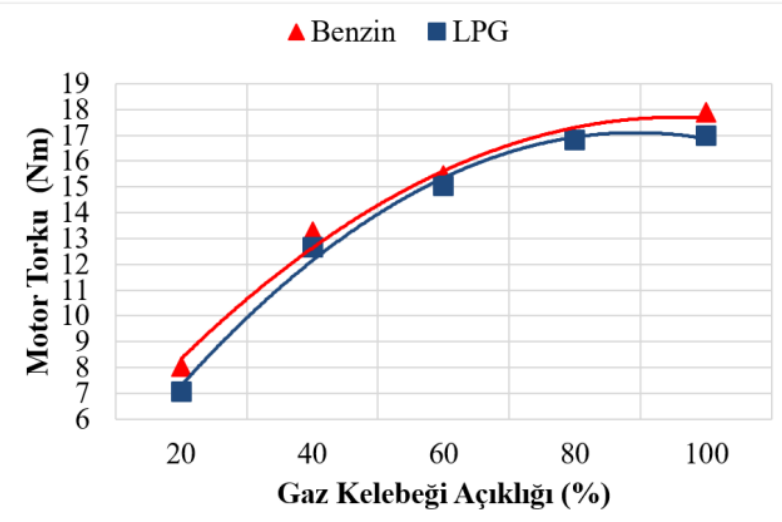

Şekil 4. Farklı GKA'larda LPG ve benzin için motor torku değişimi.

Motorun maksimum gücü LPG ve benzin için \%100 GKA'da sırayla 4,62 kW ve 4,87 kW olarak ölçülmüştür. LPG kullanımı ile ortalama motor gücü benzine oranla \%4,15 azalmıştır. Şekil 5'de artan GKA'yla her iki yakıt içinde silindire daha fazla havayakıt karışımı girdiğinden motor gücünde artış görülmüştür. Motor devrinin sabit kalmasına karşın motor torkunun artmasıyla motor gücü de artış göstermiştir. Buna ek olarak, LPG yakıtı gaz fazında olduğundan motora alınan hava kütlesi azalmakta ve volümetrik verim düşüş göstermektedir. Dolayısıyla LPG kullanımı ile motor gücü benzine oranla düşmüştür. 


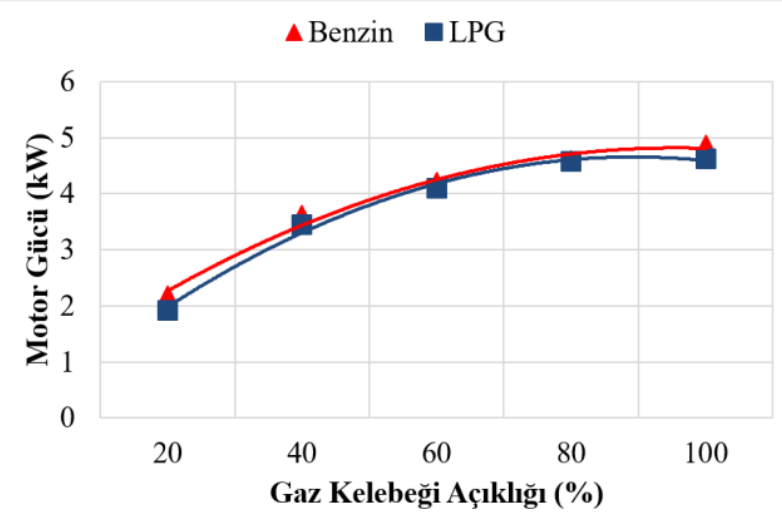

Şekil 5. Farklı GKA'larda LPG ve benzin için motor gücü değişimi.

Motorun minimum YT değeri LPG ve benzin için \%20 GKA'da sırasıyla $0,78 \mathrm{~kg} / \mathrm{h}$ ve $1,38 \mathrm{~kg} / \mathrm{h}$ olarak hesaplanmıştır. LPG ile ortalama YT benzine oranla \%16,77 azalmıştır. Şekil 6'ya göre artan GKA ile her iki yakıt türü için motora giren hava-yakıt karışımının artması YT'nin de artmasına sebep olmuştur. Bunun yanı sıra LPG'nin ısıl değeri benzinin ısıl değerinden yüksek olduğu için LPG ile açığa çıkan enerjinin benzin ile elde edilmesi için daha fazla benzin tüketilmektedir (Ceviz vd. 2015, Sulaiman et al. 2013).

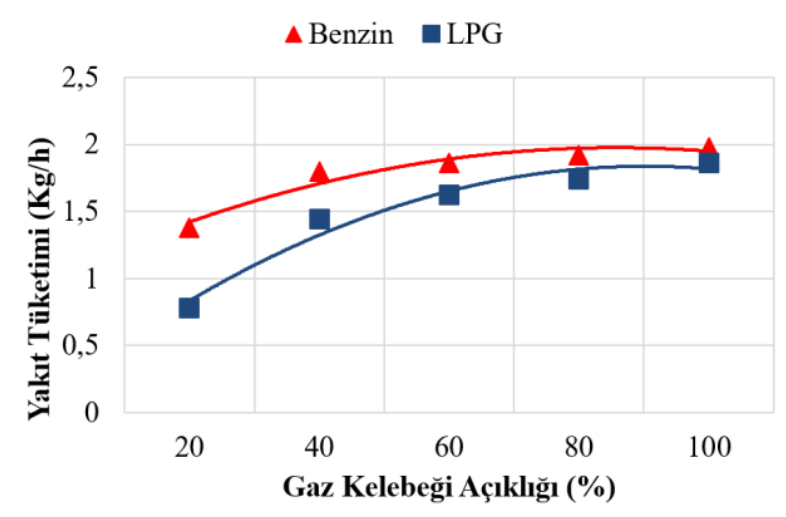

Şekil 6. Farklı GKA'larda LPG ve benzin için YT değişimi.

Motorun en düşük ÖYT değeri LPG ve benzin için sırayla \%80 GKA'da $380 \mathrm{~g} / \mathrm{kWh}$ ve \%100 GKA'da 406,18 g/kWh olarak hesaplanmıştır. LPG ile ortalama ÖYT benzine oranla \%16,45 azalmıştır. Şekil 7'de her iki yakıt için artan GKA ile ÖYT genel olarak azalmıştır. ÖYT, motor gücüyle ise ters orantılı ve anlık YT ile doğru orantılı olarak değişmektedir. Artan GKA ile motor gücünün artması ÖYT'yi azaltmıştır. Buna ek olarak, motora gaz fazında giren LPG havayla homojen olarak karışmakta ve yanma iyileşmektedir. Dolayısıyla LPG kullanımıyla benzine göre ÖYT düşsüştür (Duc and Duy 2018).

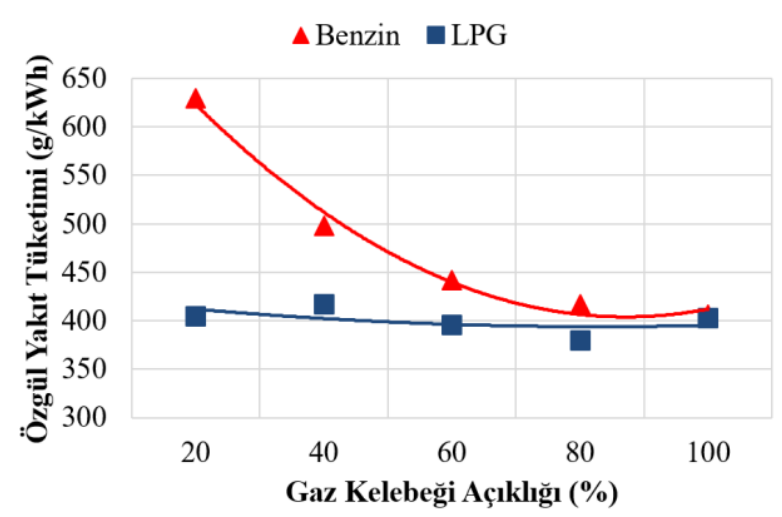

Şekil 7. Farklı GKA'larda Benzin ve LPG yakıtları için ÖYT değişimi.

\subsection{Egzoz emisyonları}

Deneylerde $\mathrm{CO}, \mathrm{CO}_{2}, \mathrm{HC}$ ve $\mathrm{NO}_{x}$ emisyonları GKA'ya bağlı olarak ölçülmüştür. Her iki yakıtla elde edilen veriler karşılaştırılmıştır.

Şekil 8'de görüldüğü gibi motorun minimum CO emisyonu LPG ve benzin için sırasıyla \%20 GKA'da $\% 3,59$ ve $\% 100$ GKA'da \%6,68 olarak ölçülmüştür. LPG ile ortalama CO emisyonu benzine oranla \%35 azalmıştır. Bununla birlikte motora gaz fazında giren LPG havayla homojen karışarak daha düzgün bir yanma sağlar. Dolayısıyla LPG kullanımıyla CO gazları benzine oranla azalmıştır (Duc and Duy 2018).

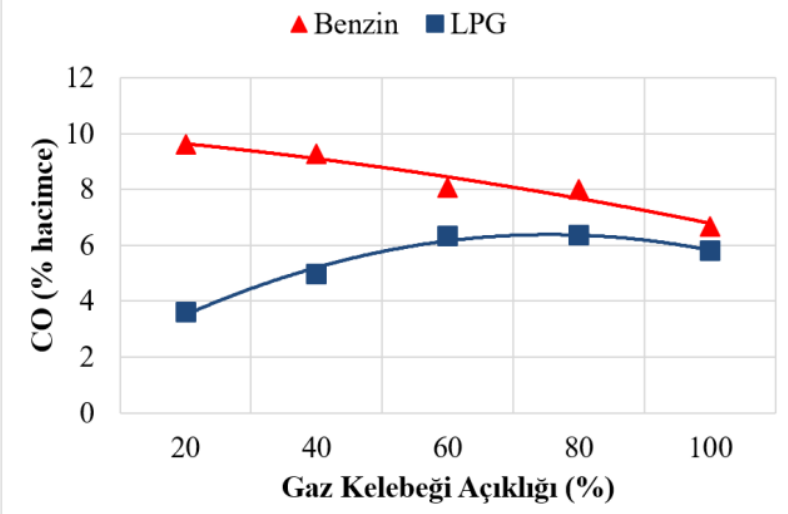

Şekil 8. Farklı GKA'larda LPG ve benzin için CO emisyonu değişimi.

Motorun minimum $\mathrm{CO}_{2}$ emisyonu $\mathrm{LPG}$ ve benzin için sırasıyla \%80 GKA'da \%6,98 ve \%40 GKA'da \%7,17 
olarak ölçülmüştür. Ortalama $\mathrm{CO}_{2}$ emisyonu LPG ile benzine oranla $\% 2,5$ azalmıştır. Şekil 6 incelendiğinde LPG için artan GKA ile \%80 GKA'ya kadar motora alınan hava-yakıt miktarının arttığı ve eksik yanmanın oluştuğu görülmektedir. Şekil 8'de yer alan $\mathrm{CO}$ emisyonları ve Şekil $9^{\prime}$ da yer alan $\mathrm{CO}_{2}$ emisyonları değişimlerinin birbiri ile zıt yönde ilerlediği belirlenmiştir. \%80 GKA'dan sonra hava yakıt karışımının daha homojen bir hale gelmesiyle yanma iyileşmiştir.

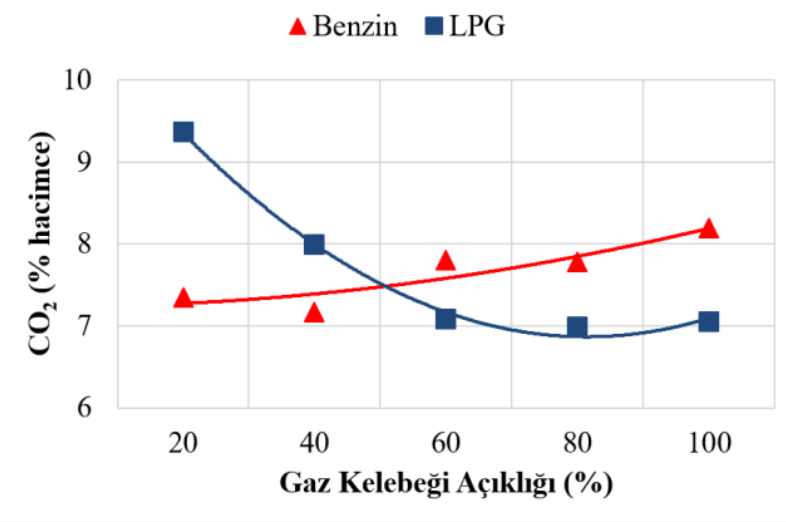

Şekil 9. Farklı GKA'larda LPG ve benzin için $\mathrm{CO}_{2}$ emisyonu değişimi.

Şekil 10'da görüldüğü gibi motorun minimum HC emisyonu LPG ve benzin için sırasıyla \%20 GKA' da 43 ppm ve \%60 GKA'da 84 ppm ölçülmüştür. LPG ile ortalama HC emisyonları benzine oranla \%35,36 düşmüştür. Motora gaz fazında giren LPG havayla homojen olarak karışarak daha iyi bir yanma sağlar. Dolayısıyla HC emisyonu LPG ile benzine oranla azalmıştır.

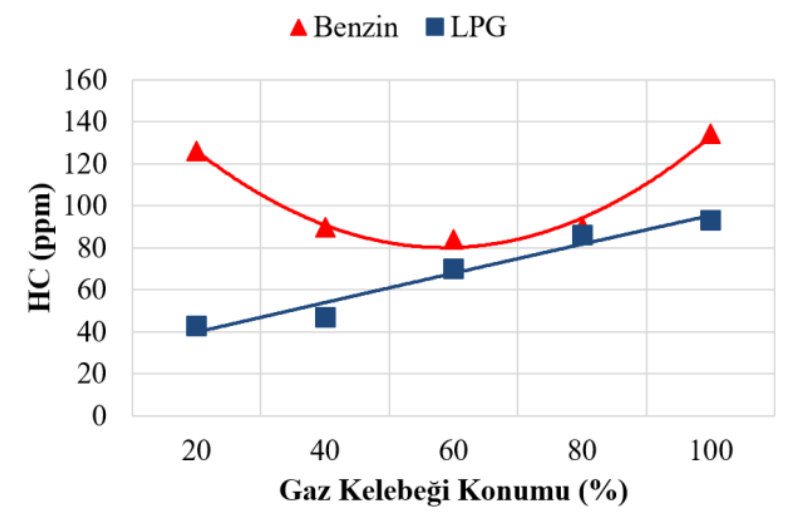

Şekil 10. Farklı GKA'larda LPG ve benzin için HC emisyonu değişimi.

Motorun minimum $\mathrm{NO}_{x}$ emisyonu $\mathrm{LPG}$ ve benzin için sırasıyla \%80 GKA'da 95,5 ppm ve \%40 GKA'da 48 ppm olarak ölçülmüştür. Ortalama $\mathrm{NO}_{x}$ emisyonu LPG ile benzine oranla \%88 artış göstermiştir. Şekil 11 incelendiğinde benzin için artan GKA ile $\mathrm{NO}_{\mathrm{x}}$ emisyonları genel bir artış göstermiştir. Artan GKA ile motora alınan hava-yakıt miktarı ve dolayısıyla yanma sonu sıcaklığı artış göstermekte, $\mathrm{NO}_{x}$ miktarı artmaktadır. LPG için \%20 - \%70 GKA'larda motorun volümetrik verimi düşük olduğundan GKA'nın artması ile $\mathrm{NO}_{x}$ emisyonlarında azalma görülmüştür.

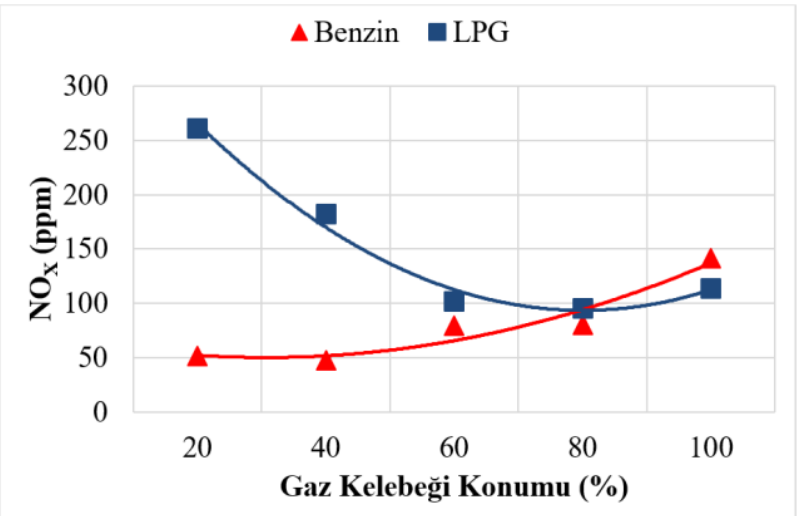

Şekil 11. Farklı GKA'larda LPG ve benzin için $\mathrm{NO}_{\mathrm{x}}$ emisyonu değişimi.

\section{Tartışma ve Sonuç}

Günümüzde içten yanmalı motorlarda egzoz emisyonlarını azaltma çalışmaları devam etmektedir. Benzin motorlarının açığa çıkardığı egzoz emisyonları alternatif bir yakıt olan LPG ile azaltılabilmektedir. LPG, benzin ile benzer motor performansı sağlamakta ve benzine oranla daha az kirletici emisyon oluşturmaktadır. Bu çalışmada, hava ile soğutulan, tek silindire sahip, 4 zamanlı ve buji ile ateşlemeli motorda alternatif bir yakıt olarak LPG yakıtının motor performansına ve egzoz emisyonlarına etkileri araştırılmıştır. Deneyler sonucunda benzin ile elde edilen motor performansının hemen hemen aynı değerlerde LPG ile de elde edilebileceği ve LPG ile daha düşük egzoz emisyon seviyelerine inildiği görülmüştür.

Ayrıca benzin motoruna yeni nesil enjeksiyon sistemlerinin kullanımı ile motor performansı ve egzoz emisyonlarının iyileşebileceği bilinmelidir. Buna ilave olarak, yüksek GKA'larda LPG'nin sıcaklığı düşmekte ve yakıt yeterince buharlaştırılamamaktadır. $\mathrm{Bu}$ nedenle yakıt 
deposunun soğuduğu ve üzerinde donmuş su damlacıkları oluşumu görülmüştür. İleride yapılacak olan deneylerde bu durum dikkate alınarak motora giren LPG'nin daha iyi ısıtılması ve dolayısıyla yanmanın iyileştirilmesi hedeflenmektedir.

\section{Teşekkür}

Bu çalışma "18.FEN.BIL.44" numaralı ve "Hava Soğutmalı Bir Motorda LPG Uygulamasının Araştırılması" isimli AKUBAP projesi tarafından desteklenmiştir. Katkılarından dolayı yazarlar olarak AKUBAP’a teşekkür ederiz.

\section{Kaynaklar}

Altun, Ş., 2009. Hayvansal yağlardan biyo-yakit üretimi ve bir dizel motorunda kullanılabilirliğinin deneysel araştırılması, Doktora Tezi, Fırat Üniversitesi Fen Bilimleri Enstitüsü, Elazığ, 137.

Aravind, B., Kishore, V.R. and Mohammad, A., 2015. Combustion characteristics of the effect of hydrogen addition on Lpg-air mixtures. International Journal of Hydrogen Energy, 40, 16605-16617.

Balki, M.K., 2005. Buji ateşlemeli motorlarda farklı sıkıştırma oranlarında Lpg kullanımının performans ve emisyonlara etkisi, Bilim Uzmanlığı Tezi, Zonguldak Üniversitesi Fen Bilimleri Enstitüsü, Zonguldak, 96.

Bilgin, H.Y., 2018. Yakıt türüne göre motosiklet seçimi ve yeni bir tasarım, Yüksek Lisans Tezi, Başkent Üniversitesi Fen Bilimleri Enstitüsü, Ankara, 96.

Ceviz, M.A., Kaleli, A. and Güner, E., 2015. Controlling LPG temperature for $\mathrm{SI}$ engine applications. Applied Thermal Engineering, 82, 298-305.

Çeçen, M., 2018. Sürdürülebilir çevre vizyonu açısından Türkiye'nin enerji politikalarında güneş enerjisinin geleceği, Yüksek Lisans Tezi, Manisa Celal Bayar Üniversitesi Sosyal Bilimler Enstitüsü, Manisa, 236.

Çelik, M., 2018. Buji ateşlemeli motorlarda ek yakıt olarak hidrojen ilavesinin vuruntuya etkisi, Yüksek Lisans Tezi, Mersin Üniversitesi Fen Bilimleri Enstitüsü, Mersin, 68.

Çınar, C., Sekmen, Y., Akbaş, A. and Balcı, M., 2001. Buji ile ateşlemeli motorlarda kısmi gaz kelebek açıklığında
Lpg kullanımı üzerine deneysel bir çalışma. Teknoloji, 1, 69-74.

Çiçek, A., 2018. Oksijen ile zenginleştirilmiş emme havasının Lpg yakıtlı buji ateşlemeli bir motorun performans ve egzoz emisyonları üzerindeki etkilerinin araştırılması, Yüksek Lisans Tezi, Uludağ Üniversitesi Fen Bilimleri Enstitüsü, Bursa, 78.

Duc, K.N. and Duy, V.N., 2018. Study on performance enhancement and emission reduction of used fuelinjected motorcycles using biofuel gasoline-Lpg. Energy For Sustainable Development, 43, 60-67.

Elnajjar, E., Selim, M.Y.E. and Hamdan, M.O., 2013. Experimental study of dual fuel engine performance using variable Lpg composition and engine parameters. Energy Conversion and Management, 76, 32-42.

Engin, P., 2018. Türkiye'de enerji yönetim sistemi uygulamalarının sanayi kuruluşları ve sanayide enerji verimliliği projeleri açısından etkinliklerinin değerlendirilmesi, Yüksek Lisans Tezi, Hacettepe Üniversitesi Sosyal Bilimler Enstitüsü, Ankara, 90.

Kart, A., 2009. LPG ile çalışan bir benzin motorunda ekserji analizi, Yüksek Lisans Tezi, Sakarya Üniversitesi Fen Bilimleri Enstitüsü, Sakarya, 102.

Keçebaş, A., Gedik, E. and Kayfeci, M., 2010. Fosil yakıtların kullanımından kaynaklanan hava kirliliği üzerine jeotermal enerji ve doğal gaz kullanımının etkisi: Afyon örneği. Electronic Journal of Machine Technologies, 7, 23-30.

Keskin, A. and Çetinkaya, S., 2001. Buji ile ateşlemeli bir benzin motorunun doğal gazla çalışır hale getirilmesinin motorun performansına etkisi. Politeknik Dergisi, 4(2), 21-26.

Kim, T.Y., Park, C., Oh, S. and Cho, G., 2016. The Effects of stratified lean combustion and exhaust gas recirculation on combustion and emission characteristics of an Lpg direct injection engine. Energy, 115, 386-396.

Koca, D.Ö., 2013. Diesel motorlarında motorin ve Lpg yakıtlarının birlikte kullanımının deneysel olarak araştırılması, Yüksek Lisans Tezi, Yıldız Teknik Üniversitesi Fen Bilimleri Enstitüsü, İstanbul, 61. 
Kocagöz, S., 2009. Çift yakıtlı (Lpg-benzin) buji ateşlemeli bir motorda hacimsel verimin performans ve emisyonlara etkisi, Yüksek Lisans Tezi, Marmara Üniversitesi Fen Bilimleri Enstitüsü, İstanbul, 80.

Mitukiewicz, G., Dychto, R. and Leyko, J., 2015. Relationship between Lpg fuel and gasoline injection duration for gasoline direct injection engines. Fuel, 153, 526-534.

Morganti, K.J., Foong, T.M., Brear, M.J., Da Silva, G., Yang, Y. and Dryer, F.L., 2013. The research and motor octane numbers of liquefied petroleum gas (LPG). Fuel, 108, 797-811.

Özgören, Y.Ö., Çetinkaya, S., Sarıdemir, S., Çiçek, A. and Kara, F., 2013. Predictive modelling of performance of a helium charged stirling engine using and artifical neural network. Energy Conversion and management, 67, 357-368.

Sayın, C., Çanakçı, M. and Kılıçaslan, İ., 2005. Benzinli bir motorda benzin+Lpg kullanımının performans ve emisyonlara etkisi. ErciyesÜniversitesi Fen Bilimleri Enstitüsü Dergisi, 21, 117-127.

Sulaiman, M.Y., Ayob, M.R. and Meran, I., 2013. Performance of single cylinder spark Ignition engine fueled by LPG. Procedia Engineering, 53, 579-585.

Szpica, D., 2018. Validation of indirect methods used in the operational assessment of LPG vapor phase pulse injectors. Measurement, 118, 253-261. 